\title{
Impact of socioeconomic status on adverse cardiac events after coronary angioplasty: a cohort study
}

\author{
Hashir Kareem, ${ }^{1}$ Prasad Narayana Shetty, ${ }_{1}$ Tom Devasia, ${ }_{1}$ Yeshwanth Rao Karkala, ${ }^{2}$ \\ Ganesh Paramasivam, ${ }^{1}$ Vasudev Guddattu, ${ }^{3}$ Ajit Singh, ${ }^{1}$ Sheetal Chauhan ${ }^{2}$
}

- Additional material is published online only. To view please visit the journal online (http://dx.doi.org/10.1136/10. 1136/heartasia-2017-010960)

'Department of Cardiology, Kasturba Medical College and Hospital, Manipal University, Manipal, India

Department of Pharmacology, Melaka Manipal Medical College, Manipal University, Manipal, India

${ }^{3}$ Department of Statistics Prasanna school of Public Health, Manipal University, Manipal, India

\section{Correspondence to} Dr Prasad Narayana Shetty, Department of Cardiology, Kasturba Medical College and Hospital, Manipal University, Manipal, Karnataka 576104 India; dr.prasadnshetty@gmail. com

HK and PNS are joint first authors.

Received 5 September 2017 Revised 11 April 2018 Accepted 9 May 2018
Check for updates

To cite: Kareem $\mathrm{H}$ Shetty PN, Devasia T, et al. Heart Asia

2018:10:e010960.

doi:10.1136/

heartasia-2017-010960
ABSTRACT

Background Socioeconomic status (SES) has been associated with adverse cardiovascular events in coronary atherosclerotic disease. However, it is unclear how SES impacts adverse cardiac events in patients treated with percutaneous coronary intervention (PCI). Methods We determined SES based on educational, economic and occupational parameters for 630 consecutive patients who underwent $\mathrm{PCl}$ at our centre between 01 June 2015 and 01 June 2016. The patients were divided into low and high SES groups, and they were followed up for 12 months. Patients were matched at baseline for demographic and procedural characteristics; multivariate analysis was used to adjust for baseline and procedural variables. Postprocedure compliance to medications was analysed. At 12 months, the primary composite end point of major adverse cardiac events (MACE) - consisting of death, non-fatal myocardial infarction, target lesion revascularisation, target vessel revascularisation — was compared between the groups.

Results The high SES group had a higher prevalence of diabetes mellitus ( $p=0.03$; OR $0.74 \%, 95 \% \mathrm{Cl} 0.53 \%$ to $1.03 \%$ ) and a stronger family history of ischaemic heart disease $(p=0.003$; OR $0.53 \%, 95 \% \mathrm{Cl} 0.33 \%$ to $0.84 \%)$. Low SES was associated with lower compliance with medication $(p=0.01$; OR $2.22 \%, 95 \% \mathrm{Cl} 1.19 \%$ to 4.15\%). At 12 months, the primary composite end point of MACE was found to be higher in the low SES group $(p=0.01)$; higher MACE was primarily driven by cardiac mortality $(p<0.001)$. Low SES was found to be an independent predictor of MACE (HR 1.84\%,95\% Cl $1.16 \%$ to $2.96 \%$ ).

Conclusion Low SES was associated with a higher incidence of major adverse cardiac events in patients undergoing $\mathrm{PCl}$ and was an independent predictor of MACE at 12 months.

\section{INTRODUCTION}

The socioeconomic status (SES) of an individual or community is a complex construct determined by several factors. Income, occupation and education are among the major indicators of SES..$^{12}$ Marital status, living environment, age, sex and ethnicity are also contributing factors that decide the socioeconomic position of an individual. ${ }^{34}$ The association between the SES of an individual and cardiovascular morbidity and mortality has been fairly well studied and documented. ${ }^{5-9}$ This link can possibly be explained by poor access to medical care, a higher prevalence of risk factors, a lower quality of life (QoL) and a lower adherence to prescribed medications among patients belonging to a lower SES.
Many studies have documented that lower SES can predict adverse cardiac events in patients with established coronary artery disease. ${ }^{410}$ However, very few studies have analysed the impact of SES on outcomes after percutaneous coronary intervention (PCI). Denvir et al, in a study conducted in the UK, found no significant association between SES and poor cardiac outcomes after PCI. But he observed that there was considerable influence of SES on post-PCI health-related QoL. ${ }^{11}$ Shimony et $a l$ in a retrospective study from Israel (they used the Israel socioeconomic index) observed worse cardiac outcomes in post-PCI patients from low SES communities during follow-up. ${ }^{3}$ Both these studies had shortcomings (the former was underpowered, and the latter was a retrospective study) and were conducted in developed countries with better access to education and medical care. Very few studies have analysed the impact of SES on outcomes in post-PCI patients in developing countries, where, we may safely presume, the impact of socioeconomic factors may be more pronounced. Ours was a prospective study conducted in a developing country that specifically explores the relation between SES and outcomes after PCI.

\section{METHODOLOGY}

Between June 2015 and June 2016, 630 consecutive patients who underwent PCI for atherosclerotic coronary artery disease (at the department of cardiology, Kasturba Hospital, Manipal, India) were recruited for this study. Demographic, anthropometric, social, economic and clinical information was collected prior to the procedure (PCI). Patients were classified as belonging to either low or high SES based on a modified version of the updated Kuppuswamy's Socioeconomic Scale. ${ }^{12}$ The Kuppuswamy's Scale, first described in 1976, is a validated tool for the assessment of SES in India, which classifies people into five groups of descending socioeconomic affluence by taking into account their educational status, occupation and income. We used the updated 2015 version redefined by Raj GM et al. ${ }^{12}{ }^{13}$ However, we simplified the scale by dividing patients into only two major groups: low SES and high SES. Among low SES patients, only those who were eligible for free treatment (including primary angioplasty with a drug-eluting stent (DES)) under state-sponsored insurance schemes were included in the study so as to avoid any bias that may occur due to a potential difference in quality of care between the two groups. Both groups received the standard treatment, as per the institutional protocol, for patients 
Table 1 Validation of MSCDC with MARS for 200 post-PTCA patients at 1 month, 6 months and 12 months follow-up

\begin{tabular}{|c|c|c|c|c|}
\hline \multicolumn{5}{|c|}{ MARS } \\
\hline MSCDC & $\begin{array}{l}\text { High drug } \\
\text { adherence } \\
\text { (N\%) }\end{array}$ & $\begin{array}{l}\text { Medium drug } \\
\text { adherence } \\
\text { (N\%) }\end{array}$ & $\begin{array}{l}\text { Low drug } \\
\text { adherence } \\
\text { (N\%) }\end{array}$ & $\boldsymbol{\kappa}$ \\
\hline \multicolumn{5}{|l|}{1 month follow-up } \\
\hline High drug adherence & $144(99.3)$ & $7(18.4)$ & 0 & 0.881 \\
\hline Medium drug adherence & $1(0.7)$ & $30(78.9)$ & 0 & \\
\hline Low drug adherence & 0 & $1(2.6)$ & $12(100)$ & \\
\hline \multicolumn{5}{|l|}{6 months follow-up } \\
\hline High drug adherence & $139(97.9)$ & 0 & 0 & 0.934 \\
\hline Medium adherence & $3(2.1)$ & $23(92)$ & 0 & \\
\hline Low drug adherence & 0 & $2(8)$ & $20(100)$ & \\
\hline \multicolumn{5}{|l|}{12 months follow-up } \\
\hline High drug adherence & $130(97.7)$ & 0 & 0 & 0.939 \\
\hline Medium adherence & $3(2.3)$ & $24(100)$ & $2(7.7)$ & \\
\hline Low drug adherence & 0 & 0 & $24(92.3)$ & \\
\hline
\end{tabular}

MSCDC, Manipal Scale for Cardiac Drug Compliance; MARS, Medication Adherence

Rating Scale; PTCA, percutaneous transluminal coronary angioplasty.

undergoing PCI. Patients were then observed for in-hospital events. Only patients who underwent successful PCI, which was defined as establishment of Thrombolysis in Myocardial Infarction 3 (TIMI 3) flow in the treated artery with no major procedure-related complications, were included in this study. Both groups received DES. Follow-up was done at 1 month, 6 months and 12 months after the procedure.

The primary end point was a composite of death, non-fatal myocardial infarction (MI), target lesion revascularisation (TLR) and target vessel revascularisation (TVR). Secondary end points included MI, repeat PCI in the same vessel and death.

To assess compliance to recommended drug therapy during follow-up, we used the Manipal Scale for Cardiac Drug Compliance (MSCDC) that we have developed and validated. Content and criterion validation of the scale was done by comparing it with the Medication Adherence Rating Scale (MARS). ${ }^{14} 15$ We compared the scores at 1 month, 6 months and 12 months of follow-up of 200 postpercutaneous transluminal coronary angioplasty (PTCA) patients. There was a good agreement of MSCDC with MARS with values of $0.881,0.934$ and 0.939 , respectively, for 1 month, 6 months and 12 months which suggested near-perfect agreement with the MARS scoring system (table 1).

We further applied this validated scale (MSCDC) on our study population and based on the score, post-PCI patients were grouped into low, medium and high compliance with medication. Adherence to lifestyle modification (LSM) advice after angioplasty was assessed by using a questionnaire that we developed and patients were divided into high, medium and low adherence groups.

Continuous variables were expressed as mean \pm SD. Categorical variables were expressed in number (percentage) and compared with the $\chi^{2}$ test; the OR for each baseline character was calculated. The impact of SES and other variables such as age, smoking, diabetes, hypertension, dyslipidaemia, number of coronary arteries involved and medication adherence on major adverse cardiac events (MACE) (death, MI and revascularisation) was determined using the Cox's proportional hazards regression model. The results were expressed as HRs and 95\% CIs where appropriate. A value of $\mathrm{p}<0.05$ was considered statistically significant. Statistical analyses were performed with SPSS software (SPSS, V.20).

\section{RESULTS}

Six hundred and thirty patients who underwent PCI for significant coronary artery disease, defined as coronary artery stenosis in one or more major arteries exceeding 70\%, were included. There were $352(55.9 \%)$ and 278 (44.1\%) patients in the high and low SES groups, respectively. Patients were followed up for 365 days/12 months.

There were no significant differences in attrition rates during follow-up between the groups $(\mathrm{p}=0.9)$. Three hundred and twenty (91\%) of high SES, 253 (91\%) of low SES post-PCI patients came for hospital follow-up. Thirty-two (9\%) of high SES and 25 (9\%) of low SES patients were lost to follow-up (OR $0.9 \%, 95 \%$ CI $0.57 \%$ to $1.71 \%$ ). A comparison of the baseline characteristics between the two groups is shown in table 2. Illiteracy and educational qualifications restricted to primary school and middle school were significantly higher among the low SES group (the corresponding ORs were 3.36 and 2.75 , respectively). The low SES group had a significantly higher number of people with occupations requiring only semiskilled and unskilled labour (OR 4.18, 2.25, respectively). The average income in the low SES group in Indian rupees (INR) was INR 5648/month (income range INR 2301-6850). The average monthly income in the high SES group was INR 11500 (income range INR 6851-11450).

Patients in the low SES group were younger $(55.9 \pm 7.5$, $56.4 \pm 6.8$ low and high SES, respectively) and had higher rates of smoking (OR 1.05\%, 95\% CI $0.73 \%$ to $1.5 \%$ ). Patients in the high SES group had a higher prevalence of type 2 diabetes mellitus (OR $0.74 \%$, 95\% CI $0.53 \%$ to $1.03 \%$ ) and a positive family history of ischaemic heart disease (IHD) (OR 0.53\%, 95\% CI $0.33 \%$ to $0.84 \%)$. One hundred and seventy (48.2\%) patients in the high SES group and $148(53.2 \%)$ in the low SES group had presented with ST elevation myocardial infarction (STEMI). Almost all of these patients were treated with primary PCI: 166 (47.1\%) in the high SES and 146 (52.5\%) in the low SES (OR $1.23 \%, 95 \%$ CI $0.89 \%$ to $1.7 \%$ ) groups (table 2 ). Both groups received dual antiplatelet therapy and high dose statin therapy (OR $1.58 \%$, 95\% CI $0.08 \%$ to $3.7 \%$ ). There was no significant difference observed in the prescription patterns of medications between the two groups: angiotensin II receptor blockers (ARB's) (OR $0.99 \%$, 95\% CI $0.69 \%$ to $1.41 \%$ ), ACE-inhibitors (ACE-I) (OR $0.91 \%, 95 \%$ CI $0.63 \%$ to $1.31 \%$ ), $\beta$-blockers (OR $1.29 \%, 95 \%$ CI $0.92 \%$ to $1.80 \%$ ), calcium channel blockers (OR $0.90 \%, 95 \%$ CI $0.57 \%$ to $1.40 \%$ ), diuretics (OR $1.32 \%, 95 \%$ CI $0.90 \%$ to $1.93 \%$ ) and nitrates (OR 0.88\%, 95\% CI $0.59 \%$ to $1.31 \%$ ). Adherence to therapeutic LSM after angioplasty was significantly poorer in the low SES group when compared with the high SES group (low LSM: 46 (13.1\%) vs $67(23.8 \%)$ in high vs low SES, OR=2.7; medium LSM: 124 $(35.2 \%)$ vs $113(40.8 \%)$ in high and low SES, OR=1.69; high LSM: $182(51.8 \%)$ vs 98(35.4\%) in high vs low SES, $\mathrm{p}<0.001)$ (table 2).

Patients with high adherence to medication (as evidenced by a score of $<1$ on MSCDC) and medium adherence (a score of 1-3 on MSCDC) were higher in the high SES group. Concomitantly, patients with low adherence (as evidenced by a score of $>3$ on MSCDC) were found to be higher in the low SES category (OR $1.049 \%$, $95 \%$ CI $0.58 \%$ to $1.88 \%$ and OR $2.22 \%$, $95 \%$ CI $1.19 \%$ to $4.15 \%$ for medium and low adherence, respectively) (table 3). Patients in the low SES category were more likely to be non-compliant to medication $(p=0.01)$ as measured by continuous days of treatment.

At 12 months follow-up, the composite end point of death, non-fatal MI, TLR, TVR was significantly higher in the low 
Table 2 Baseline characteristics of percutaneous transluminal coronary angioplasty (PTCA) patients of high and low socioeconomic status (SES)

\begin{tabular}{|c|c|c|c|}
\hline & $\begin{array}{l}\text { High SES } \\
\mathrm{n}=352(\%)\end{array}$ & $\begin{array}{l}\text { Low SES } \\
n=278(\%)\end{array}$ & $\begin{array}{l}\text { OR } \\
(95 \% \mathrm{Cl})\end{array}$ \\
\hline Age & $56.4 \pm 6.8$ & $55.9 \pm 7.5$ & 0.3 \\
\hline Male & $274(77.8)$ & 209 (75.1) & 0.86 (0.58 to 1.27$)$ \\
\hline Female & $78(22.1)$ & $69(24.8)$ & 1 \\
\hline Mixed diet & $246(69.8)$ & $214(76.9)$ & 1.44 (0.99 to 2.1$)$ \\
\hline Veg & $106(30.1)$ & $64(23)$ & 1 \\
\hline \multicolumn{4}{|l|}{ Education ( $p<0.001$ ) } \\
\hline $\begin{array}{l}\text { Profession/honour } \\
\text { Graduate/postgraduate }\end{array}$ & $53(15)$ & $15(5.4)$ & 1 \\
\hline $\begin{array}{l}\text { Intermediate/post high } \\
\text { school }\end{array}$ & $35(9.9)$ & $8(2.9)$ & 0.81 (0.26 to 2.30$)$ \\
\hline High school certificate & $80(22.8)$ & $31(11.2)$ & $1.36(0.64$ to 3.0$)$ \\
\hline Middle school certificate & $18(5.2)$ & $14(5.0)$ & $2.75(1,7.44)$ \\
\hline Primary school certificate & $125(35.5)$ & $119(42.8)$ & 3.36 (1.75 to 6.76$)$ \\
\hline Illiterate & $41(11.6)$ & $91(32.7)$ & 7.84 (3.79 to 16.62$)$ \\
\hline \multicolumn{4}{|l|}{ Occupation $(p<0.001)$} \\
\hline Profession/semiprofession & $30(8.5)$ & $8(2.8)$ & 0.42 (0.16 to 1.02 ) \\
\hline Clerical/shop owner/farmer & $126(35.8)$ & $84(30.2)$ & 1.05 (0.67 to 1.65$)$ \\
\hline Skilled worker & $48(13.6)$ & $24(8.6)$ & 0.79 (0.42 to 1.47$)$ \\
\hline Semiskilled worker & $35(9.9)$ & $50(18)$ & 2.25 (1.26 to 4.02$)$ \\
\hline Unskilled worker & $20(5.7)$ & $53(19.1)$ & 4.18 (2.19 to 8.11$)$ \\
\hline Unemployed/housewife & $93(26.5)$ & $59(21.2)$ & 1 \\
\hline \multicolumn{4}{|l|}{ Income $(p<0.001)$ (INR) } \\
\hline$>22851$ & $69(19.6)$ & $10(3.5)$ & 0.17 (0.07 to 0.36$)$ \\
\hline $17151-22850$ & $40(11.3)$ & $11(3.9)$ & 0.32 (0.07 to 0.36$)$ \\
\hline $11451-17150$ & $46(13.1)$ & $33(11.8)$ & 0.83 (0.46 to 1.50$)$ \\
\hline $6851-11450$ & $73(20.7)$ & $71(25.5)$ & 1.32 (0.69 to 1.84 ) \\
\hline $2301-6850$ & $46(13)$ & $86(30.9)$ & 2.17 (1.3 to 3.69$)$ \\
\hline$<2300$ & $78(22.1)$ & $67(24.1)$ & 1 \\
\hline $\mathrm{F} h / \mathrm{olHD}$ & $75(21.3)$ & $35(12.5)$ & 0.53 (0.33 to 0.84$)$ \\
\hline Smoking & $103(29.3)$ & $84(31)$ & 1.05 (0.73 to 1.50$)$ \\
\hline Hypertension & $204(57.9)$ & $152(54.7)$ & 0.88 (0.63 to 1.22$)$ \\
\hline Diabetes & $172(48.8)$ & $115(41.4)$ & 0.74 (0.53 to 1.03$)$ \\
\hline Dyslipidaemia & $27(7.7)$ & $18(6.5)$ & 0.83 (0.42 to 1.61$)$ \\
\hline Prediet control & $157(44.6)$ & $80(28.8)$ & 0.5 (0.35 to 0.71$)$ \\
\hline $\begin{array}{l}\text { Preblood pressure } \\
\text { control }\end{array}$ & $169(48)$ & $107(38.5)$ & 0.68 (0.48 to 0.94$)$ \\
\hline Preblood sugar control & $154(43.8)$ & $84(30)$ & 1.79 (1.27 to 2.73$)$ \\
\hline Prephysical exercise & $99(28.1)$ & $53(19)$ & 0.60 (0.4 to 0.89$)$ \\
\hline \multicolumn{4}{|l|}{ Pre-PCI lifestyle $(p=0.005)$} \\
\hline Low lifestyle & $219(62.2)$ & $205(73.8)$ & 1 \\
\hline Medium lifestyle & $126(35.8)$ & $66(23.7)$ & 0.55 (0.38 to 0.80$)$ \\
\hline High lifestyle & $7(2)$ & $7(2.5)$ & 1.06 (0.21 to 3.63$)$ \\
\hline \multicolumn{4}{|l|}{ NYHA class $(\mathrm{p}=0.005)$} \\
\hline (III-IV) & $106(30.1)$ & $113(32.1)$ & 0.62 (0.44 to 0.88 ) \\
\hline \multicolumn{4}{|l|}{$\mathrm{PCl}$ indication $(\mathrm{p}=0.3)$} \\
\hline STEMI & $170(48.2)$ & $148(53.2)$ & 1.55 (0.96 to 2.53$)$ \\
\hline NSTEMI & $93(26.4)$ & $73(26.2)$ & 1.40 (0.82 to 2.40$)$ \\
\hline UA & $23(6.5)$ & $20(7.1)$ & 1.55 (0.70 to 3.39$)$ \\
\hline SA & $66(18.7)$ & $37(13.3)$ & 1 \\
\hline Primary PCl & $166(47.1)$ & $146(52.5)$ & $\begin{array}{l}1.23(0.89 \text { to } 1.7) \\
(p=0.18)\end{array}$ \\
\hline Throbolysed & $4(1.1)$ & $2(0.7)$ & $\begin{array}{l}0.63(0.05 \text { to } 4.43) \\
(p=0.5)\end{array}$ \\
\hline \multicolumn{4}{|l|}{ LV function ( $\mathrm{p}=0.28)$} \\
\hline Normal LV & $282(80.1)$ & $213(76.6)$ & 0.81 (0.54 to 1.21$)$ \\
\hline Mild LV dysfunction & 70 (19.9) & $65(23.4)$ & 1.22 (0.82 to 1.83$)$ \\
\hline
\end{tabular}

Table 3 Characteristics of post-PTCA patients of high and low SES

\begin{tabular}{|c|c|c|c|}
\hline & $\begin{array}{l}\text { High SES } \\
\mathrm{n}=352(\%)\end{array}$ & $\begin{array}{l}\text { Low SES } \\
n=278(\%)\end{array}$ & $\begin{array}{l}\text { OR } \\
(95 \% \mathrm{Cl})\end{array}$ \\
\hline \multicolumn{4}{|l|}{ Vessel-involved $(p=0.49)$} \\
\hline SVD & $156(44.4)$ & $119(42.8)$ & 1 \\
\hline DVD & $129(36.7)$ & $112(40.2)$ & $1.18(0.79$ to 1.63$)$ \\
\hline MVD & $66(18.8)$ & $47(17)$ & 0.86 (0.53 to 1.39$)$ \\
\hline \multicolumn{4}{|l|}{ Culprit vessel $(p=0.95)$} \\
\hline LAD & $198(56.3)$ & $159(57.2)$ & 1 \\
\hline RCA & $114(32.4)$ & $87(31.3)$ & 0.95 (0.66 to 1.36$)$ \\
\hline LCX & $40(11.3)$ & $32(11.5)$ & 0.99 (0.57 to 1.70$)$ \\
\hline \multicolumn{4}{|l|}{ Baseline prescription pattern } \\
\hline Aspirin & $352(100)$ & $278(100)$ & \\
\hline Antiplatelet & $352(100)$ & $278(100)$ & \\
\hline Clopidogrel & $167(47.4)$ & $127(45.7)$ & 0.93 (0.67 to 1.29$)$ \\
\hline Ticagrelor & $185(52.6)$ & $151(54.3)$ & 1.04 (0.75 to 1.45$)$ \\
\hline Statin & $350(99.4)$ & $277(99.6)$ & $1.58(0.08$ to 3.7$)$ \\
\hline ACE-I & $105(29.8)$ & $78(28.1)$ & 0.91 (0.63 to 1.31 ) \\
\hline ARBs & $108(30.7)$ & $85(30.6)$ & 0.99 (0.69 to 1.41$)$ \\
\hline$\beta$-blockers & $204(58)$ & $178(64)$ & $1.29(0.92$ to 1.80$)$ \\
\hline Ca channel blockers & $62(17.6)$ & $45(16.2)$ & 0.90 (0.57 to 1.40$)$ \\
\hline Diuretics & $79(22.4)$ & $77(27.7)$ & $1.32(0.90$ to1.93) \\
\hline Nitrates & $81(23)$ & $58(20.9)$ & 0.88 (0.59 to 1.31$)$ \\
\hline \multicolumn{4}{|l|}{ Follow-up $(p=0.96)$} \\
\hline Hospital follow-up & 320 (91) & $253(91)$ & 1 \\
\hline Lost of follow-up & $32(9.0)$ & $25(9.0)$ & 0.9 (0.57 to 1.71$)$ \\
\hline \multicolumn{4}{|c|}{ Post-PCI LSM at 12 months $(p<0.001)$} \\
\hline High LSM & $182(51.7)$ & $98(35.4)$ & 1 \\
\hline Medium LSM & $124(35.2)$ & $113(40.8)$ & 1.69 (1.18 to 2.41$)$ \\
\hline Low LSM & $40(13.1)$ & $67(23.8)$ & 2.7 (1.72 to 4.23$)$ \\
\hline \multicolumn{4}{|l|}{ Medical adherence $(p=0.037)$} \\
\hline High-medical adherence & $249(83.8)$ & $174(77.7)$ & 1 \\
\hline $\begin{array}{l}\text { Medium-medical } \\
\text { adherence }\end{array}$ & $30(10.1)$ & $22(9.8)$ & 1.04 (0.58 to 1.88$)$ \\
\hline Low-medical adherence & $18(6.1)$ & $28(12.5)$ & $2.22(1.194 .15)$ \\
\hline
\end{tabular}

ACE-I-Angiotensin converting enzyme - inhibitor.; ARB, angiotensin II receptor blockers; DVD-double vessel disease; LAD-left anterior descending; LCX-left circumflex; LSMlifestyle modification; MVD- Multiple vessel diseases; RCA-right coronary artery; SESsocioeconomic status; SVD-single vessel disease

SES group $(45(16.2 \%)$ in the low SES group and $32(9.1 \%)$ in the high SES group; $\mathrm{p}=0.01)$ and this was predominantly driven by higher mortality in the low SES group (20 (7.2\%) vs $6(1.7 \%)$; $\mathrm{p}<0.001)$. The composite end point (MACE) at 1 month and 6 months was not significantly different in either group (14 (4\%) vs $17(6.1 \%) ; p=0.2$ and $12(3.4 \%)$ vs $18(6.5 \%) ; p=0.9$ in the high and low SES groups at 1 month and 6 months, respectively) (table 4).

The secondary end point of death was significantly higher in the low SES group at 12 months $(20(7.2 \%)$ in the low SES group vs $6(1.7 \%)$ in the high SES group; $\mathrm{p}=0.001)$. However, repeat

Table 4 Post-PTCA MACE at different follow-ups

\begin{tabular}{llll}
\hline Composite MACE & $\begin{array}{l}\text { High SES } \\
\mathbf{n}=352(\%)\end{array}$ & $\begin{array}{l}\text { Low SES } \\
\mathbf{n = 2 7 8 ( \% )}\end{array}$ & P value \\
\hline $\begin{array}{l}\text { Overall MACE at 12 } \\
\text { months }\end{array}$ & $32(9.1)$ & $45(16.2)$ & 0.01 \\
At 6 months & $12(3.4)$ & $18(6.5)$ & 0.9 \\
At 1 month & $14(4)$ & $17(6.1)$ & 0.2
\end{tabular}

MACE, major adverse cardiac events; PTCA, percutaneous transluminal coronary angioplasty; SES, socioeconomic status. 
Table 5 Unadjusted event rates for secondary end points

\begin{tabular}{lcll}
\hline Event & $\begin{array}{l}\text { High SES } \\
\mathbf{n}=352(\%)\end{array}$ & $\begin{array}{l}\text { Low SES } \\
\mathbf{n}=\mathbf{2 7 8}(\%)\end{array}$ & P value \\
\hline Death & $6(1.7)$ & $20(7.2)$ & 0.001 \\
Non-fatal MI & $13(3.7)$ & $14(5.1)$ & 0.43 \\
TLR & $5(1.4)$ & $7(2.5)$ & 0.38 \\
TVR & $8(2.3)$ & $5(1.8)$ & 0.78 \\
\hline
\end{tabular}

$\mathrm{MI}$, myocardial infarction; SES, socioeconomic status; TLR, transient lesion revascularisation; TVR, transient vessel revascularisation.

PCI (TLR $5(1.4 \%)$ vs $7(2.5 \%)$ and TVR $8(2.3 \%)$ vs $5(1.8 \%))$ and recurrent MI $(13(3.7 \%)$ vs $14(5.1 \%)$ in the high and low SES groups, respectively) were not significantly different between the groups (table 5).

After correction for baseline variables (table 6) like age, gender, family history, smoking, diabetes, hypertension, dyslipidaemia, low SES, adherence to medication, STEMI, presence of multivessel disease and LAD as the culprit vessel, we found that the independent predictors of MACE were low SES (HR $1.84 \%$, 95\% CI 1.16\% to $2.91 \%$ ) and STEMI (HR 2.20\%, 95\% CI $0.98 \%$ to $4.93 \%$ ).

\section{DISCUSSION}

Cardiovascular disease (CVD) is the leading cause of mortality and morbidity in Western countries; more recently it has made its way into developing countries. ${ }^{16}$ Recent data suggest that there is a rise in the occurrence of cardiovascular disease-related morbidity and mortality across the range of SES, as demarcated by income, occupation and low educational level. ${ }^{61718}$ Earlier

\begin{tabular}{|c|c|c|c|}
\hline $\begin{array}{l}\text { Variable } \\
\text { (Reference range) }\end{array}$ & $\begin{array}{l}\text { Unadjusted } \\
\mathrm{HR}(95 \% \mathrm{Cl})\end{array}$ & $\begin{array}{l}\text { Adjusted } \\
\text { HR }(95 \% \mathrm{Cl})\end{array}$ & $P$ value \\
\hline Low SES (high SES) & 1.84 (1.16 to 2.91$)$ & 1.74 (1.10 to 2.77 ) & 0.009 \\
\hline Male gender (female gender) & 0.72 (0.42 to 1.23$)$ & 0.72 (0.14 to 1.23 ) & 0.231 \\
\hline T2DM (No T2DM) & 1.02 (0.62 to 1.66$)$ & 1.01 (0.59 to 1.7$)$ & 0.92 \\
\hline $\begin{array}{l}\text { Hypertension (no } \\
\text { hypertension) }\end{array}$ & $1.40(0.84$ to 2.35$)$ & 1.32 (0.77 to 2.25 ) & 0.19 \\
\hline Smoker (non-smoker) & 0.76 (0.44 to 1.31$)$ & 0.88 (0.5 to 1.56 ) & 0.33 \\
\hline $\begin{array}{l}\text { Dyslipidaemia (no } \\
\text { dyslipidaemia) }\end{array}$ & $0.70(0.25$ to 1.92$)$ & 0.67 (0.24 to 1.87$)$ & 0.49 \\
\hline Veg Diet (mixed diet) & 1.61 (0.89 to 2.92$)$ & 1.76 (0.96 to 3.22$)$ & 0.06 \\
\hline $\mathrm{H} / \mathrm{olHD}$ (no H/o IHD) & $0.50(0.24$ to 1.05$)$ & 0.52 (0.24 to 1.09$)$ & 0.07 \\
\hline STEMI (non STEMI) & 2.20 (0.98 to 4.93$)$ & 2.20 (0.99 to 4.87$)$ & 0.04 \\
\hline NSTEMI (non NSTEMI) & 1.39 (0.59 to 3.37$)$ & 1.61 (0.67 to 3.87 ) & 0.45 \\
\hline UA (non-UA) & $1.66(0.52$ to 5.32$)$ & $1.73(0.55$ to 5.46$)$ & 0.39 \\
\hline SA (non-SA) & 1 & 1 & 0.07 \\
\hline LAD (non- LAD) & 0.93 (0.46 to 1.87$)$ & 0.84 (0.42 to 1.68$)$ & 0.84 \\
\hline RCA (non-RCA) & 1.02 (0.48 to 2.14$)$ & 0.87 (0.42 to 1.82$)$ & 0.957 \\
\hline LCX (non-LCX) & 1 & 1 & 0.849 \\
\hline SVD (non-SVD) & 0.92 (0.48 to 1.78$)$ & 1.02 (0.54 to 1.95$)$ & 0.81 \\
\hline DVD (non-DVD) & $0.87(0.45$ to 1.70$)$ & 1.04 (0.54 to 1.99$)$ & 0.699 \\
\hline MVD (non MVD) & 1 & 1 & 0.831 \\
\hline $\begin{array}{l}\text { Medical adherence (non- } \\
\text { medical adherence) }\end{array}$ & 0.80 (0.50 to 1.28$)$ & 0.81 (0.5 to 1.2$)$ & 0.3 \\
\hline
\end{tabular}

DVD, double vessel disease; H/o IHD, history of ischaemic heart disease; LAD, left anterior descending; LCX, left circumflex; MVD, Multiple vessel diseases; NSTEMI, nonSTEMI; RCA, right coronary artery; SA, stable angina; SES, socioeconomic

status; STEMI, ST elevation myocardial infarction; SVD, single vessel disease;

T2DM, Type 2 diabetes mellitus; UA, unstable angina. studies from the UK and USA showed a positive association between higher SES and cardiovascular disease. More recently, however, a reversal of this trend has been noticed in those countries with similar patterns emerging in countries like New Zealand, Australia and the Scandinavian countries. ${ }^{19}$

A study conducted by the Canadian Heart Health Surveys Research Group among 23129 Canadian residents aged between 18 years and 74 years from 1986 to 1992 concluded that people with low SES, particularly people with less education, had worse cardiac outcomes and they also had less awareness about CVD risk factors. ${ }^{2}$ A large cohort study, involving 303036 people, conducted among the Asian and Australian populations demonstrated that poor educational status was strongly associated with a higher risk of CVD or premature death in the general population. ${ }^{8}$ A low SES has been shown to be an independent predictor of cardiovascular disease and its risk factors. ${ }^{591719}$

However, few studies have looked specifically at the relationship between SES and MACE following coronary angioplasty. ${ }^{3} 1011$ Manderbacka et al observed in a cohort study in Finnish residents who underwent coronary revascularisation between 1998 and 2010 that the cardiac mortality rate was significantly higher in the lowest income group. ${ }^{10}$ Shimony et al demonstrated a higher incidence of cardiovascular risk factors, higher prevalence of non-compliance with prescribed medication and a higher incidence of MACE in the low socioeconomic category patients in a study conducted in Israel. ${ }^{3}$

In our study, significant differences in baseline characteristics, compliance with therapy and clinical outcomes were observed between patients belonging to high and low socioeconomic (SE) groups. High SES patients had a higher incidence of diabetes and family history of IHD. Patients in the low SES group were less compliant to medication and were also less likely to adhere to therapeutic LSM advice after angioplasty. At 12 months follow-up, the primary composite end point of death, repeat revascularisation and recurrent MI was found to be higher in the low SES group. After correction for baseline differences, low SES was found to be an independent predictor of MACE during follow-up.

In another earlier study, Denvir et al found no significant difference in adverse cardiac outcomes after PCI between patients of low and high SES in the UK. ${ }^{11}$ The difference in results between this study and ours might be explained by the difference in social, economic and educational circumstances that prevail in developed and developing countries. Moreover, this study, in contrast to ours, was conducted in the pre-DES era.

Several studies have reported an association between low SES and poor drug compliance. ${ }^{20-22}$ We found significantly lower compliance with medications among patients of low SES. But when progressively adjusted for risk factors using the Cox's model, drug non-adherence was not found to be an independent predictor of MACE in our study. However, low adherence to guideline-recommended medications has repeatedly been shown to be a major risk factor for adverse long-term outcomes ${ }^{322}$ and can be considered one of the possible explanations for the adverse outcomes observed. Moreover, we observed that adherence to therapeutic lifestyle modification was significantly poorer in the low SES group. We hypothesise that this too might have contributed to the findings in our study. Woodward et al demonstrated that poor educational status (which was considered a surrogate for SES), especially in Asian countries like China and Thailand, correlated strongly with both all-cause mortality and cardiac mortality. ${ }^{23}$ However, the exact mechanism for the increased cardiac mortality observed in the low SES group is not clear. Further research is warranted in this direction. 
Key messages

\section{What is already known about this subject?}

- Several studies have linked poor socioeconomic status (SES) to adverse outcomes in patients with coronary atherosclerotic disease (CAD). Low SES has been identified as a risk factor for poor outcomes in patients with CAD.

- A few studies (mostly from developed nations) have also looked at the correlation between SES and outcomes after revacularisation (percutaneous coronary intervention (PCI)/coronary artery bypass graft (CABG)) but the data are scant and inconsistent.

What does this study add?

- Very few, if any, studies have specifically looked at the role of SES in predicting outcomes after $\mathrm{PCl}$ in developing countries like India. Earlier studies had been conducted in developed nations like the UK and Israel. Moreover, our study, unlike previous studies on the subject, is a prospective cohort study with a 12-month follow-up with major adverse cardiac events (MACE) after $\mathrm{PCl}$ as a primary end point. We also looked at compliance to medication among patients of poor SES.

\section{How might this impact on clinical practice?}

- Our study shows that SES should be considered a risk factor for adverse outcomes after $\mathrm{PCl}$ in developing countries like India. One can make a case for incorporating SES into MACE risk calculations. We also found poor compliance to medications and poor adherence to therapeutic lifestyle modification among patients of low SES. Therefore, A more rigid follow-up regimen and strict counselling regarding adherence to medications after $\mathrm{PCl}$ as well as addressing their economic concerns may go a long way in improving long-term outcomes in patients of low SES.

SES has been evaluated as a potential risk factor for coronary atherosclerotic disease in addition to the conventional risk factors. $^{2425}$ Our study shows that SES should be considered a risk factor for adverse outcomes after PCI as well. One can make a case for incorporating SES into MACE risk calculations and thereby helping the physician to improve treatment. A rigid follow-up regimen and strict counselling regarding adherence to medications after PCI as well as addressing their economic concerns may go a long way in improving long-term outcomes in patients of low SES. From a public health perspective, it may be stressed that it remains the duty of the society and the government to address potential inequalities in healthcare provision and utilisation that may exist between people of different socioeconomic strata so that the benefits of modern medical therapy may reach everyone equally.

\section{Conclusion}

The association between SES and adverse cardiac events in post-PCI patients appears to be significant and cannot be ignored. Low SES, in our study, was associated with lower adherence to medication and higher mortality after PCI. Further research is required to delineate the mechanisms that would help explicate the link between SES and mortality.

Contributors Concepts: HK, PNS, TD. Design: HK, PNS, TD, YRK, GP. Literature search: HK, PNS, TD, YRK, GP, VG, AS. Data acquisition: HK, PNS, TD, YRK, GP. Data analysis: HK, PNS, TD, YRK, GP, VG. Statistical analysis: HK, PNS, TD, YRK. Manuscript preparation: HK, PNS, TD, YRK, GP, VG. Manuscript editing: HK, PNS, TD, YRK. Manuscript review: HK, PNS, TD, YRK, GP, VG, AS, SC. Guarantor: HK, PNS, TD.
Funding The authors have not declared a specific grant for this research from any funding agency in the public, commercial or not-for-profit sectors.

Competing interest None declared.

Patient consent Parental/guardian consent obtained.

Ethics approval Kasturba Medical College Ethics committee.

Provenance and peer review Not commissioned; externally peer reviewed.

(c) Article author(s) (or their employer(s) unless otherwise stated in the text of the article) 2018. All rights reserved. No commercial use is permitted unless otherwise expressly granted.

\section{REFERENCES}

1 Luepker RV, Rosamond WD, Murphy R, et al. Socioeconomic status and coronary heart disease risk factor trends. The Minnesota Heart Survey. Circulation 1993;88:2172-9.

2 Potvin L, Richard L, Edwards AC. Knowledge of cardiovascular disease risk factors among the Canadian population: relationships with indicators of socioeconomic status. CMAJ 2000;162(9 Suppl):S5-S11.

3 Shimony A, Zahger D, llia R, et al. Impact of the community's socioeconomic status on characteristics and outcomes of patients undergoing percutaneous coronary intervention. Int J Cardiol 2010;144:379-82.

4 Clark AM, DesMeules M, Luo W, et al. Socioeconomic status and cardiovascular disease: risks and implications for care. Nat Rev Cardiol 2009;6:712-22.

5 Fiscella K, Tancredi D. Socioeconomic status and coronary heart disease risk prediction. JAMA 2008;300:2666-8.

6 Rawshani A, Svensson AM, Rosengren A, et al. Impact of socioeconomic status on cardiovascular disease and mortality in 24,947 individuals with type 1 diabetes. Diabetes Care 2015:38:1518-27.

7 Phillips JE, Klein WM. Socioeconomic Status and coronary heart disease risk: the role of social cognitive factors. Soc Personal Psychol Compass 2010;4:704-27.

8 Woodward M, Peters SAE, Batty GD, et al. Socioeconomic status in relation to cardiovascular disease and cause-specific mortality: a comparison of Asian and Australasian populations in a pooled analysis. BMJ Open 2015;5:e006408.

9 Kaplan GA, Keil JE. Socioeconomic factors and cardiovascular disease: a review of the literature. Circulation 1993:88:1973-98

10 Manderbacka K, Arffman M, Lumme S, et al. Are there socioeconomic differences in outcomes of coronary revascularizations--a register-based cohort study. Eur J Public Health 2015;25:984-9.

11 Denvir MA, Lee AJ, Rysdale J, et al. Influence of socioeconomic status on clinical outcomes and quality of life after percutaneous coronary intervention. J Epidemiol Community Health 2006;60:1085-8.

12 Raj GM, Shilpa S, Maheshwaran R. Revised socio-economic status scale for urban and rural India: Revision for 2015. Socioeconomica 2015;4:167-74.

13 Shilpa S, Maheshwaran R. Revised socio-economic status scale for urban and rural india-revision for 2015, 2015.

14 Thompson K, Kulkarni J, Sergejew AA. Reliability and validity of a new Medication Adherence Rating Scale (MARS) for the psychoses. Schizophr Res 2000;42:241-7.

15 Fialko L, Garety PA, Kuipers E, et al. A large-scale validation study of the Medication Adherence Rating Scale (MARS). Schizophr Res 2008;100:53-9.

16 Eldesouky El. Research article impact of educational program for anginal patients about preventive measures of angina pectoris, 2016.

17 Franks P, Tancredi DJ, Winters P, et al. Including socioeconomic status in coronary heart disease risk estimation. Ann Fam Med 2010;8:447-53.

18 Psaltopoulou T, Hatzis G, Papageorgiou N, et al. Socioeconomic status and risk factors for cardiovascular disease: Impact of dietary mediators. Hellenic J Cardiol 2017; 58:32-42.

19 Tarasiuk A, Greenberg-Dotan S, Simon T, et al. Low socioeconomic status is a risk factor for cardiovascular disease among adult obstructive sleep apnea syndrome patients requiring treatment. Chest 2006;130:766-73.

20 Jimmy B, Jose J. Patient medication adherence: measures in daily practice. Oman Med J 2011;26:155-9.

21 Mishra P, Hansen EH, Sabroe S, et al. Socio-economic status and adherence to tuberculosis treatment: a case-control study in a district of Nepal. Int J Tuberc Lung Dis 2005;9:1134-9.

22 Alter DA, Naylor CD, Austin P, et al. Effects of socioeconomic status on access to invasive cardiac procedures and on mortality after acute myocardial infarction. N Engl J Med 1999;341:1359-67.

23 Woodward M, Peters SA, Batty GD, et al. Socioeconomic status in relation to cardiovascular disease and cause-specific mortality: a comparison of Asian and Australasian populations in a pooled analysis. BMJ Open 2015;5:e006408.

24 Mack M, Gopal A, Epidemiology GA. Epidemiology, traditional and novel risk factors in coronary artery disease. Heart Fail Clin 2016;12:1-10.

25 Mehta JL, Saldeen TG, Rand K. Interactive role of infection, inflammation and traditional risk factors in atherosclerosis and coronary artery disease. J Am Coll Cardiol 1998;31:1217-25. 